\section{LAS META DECISIONES Y LA TEORÍA DE LA RACIONALIDAD INSTRUMENTAL MÍNIMA}

\author{
DECISION GOALS AND BOUNDED RATIONALITY
}

\author{
Patricia Bonatti
}

\section{Resumen}

El proceso decisorio es el proceso que más estudios atesora y que atrae además a más profesionales de distintas disciplinas. Economistas, administradores, médicos, psicólogos, ingenieros, neurólogos y hasta cardiólogos, todos aportan a mejorar este proceso, tan omnipresente en nuestras vidas. Nos preocupa en este proceso analizar la calificación de racional o irracional según distintas corrientes de pensamiento, en el marco de la teoría de la decisión.

Abordaremos un poco de historia y caracterización de la problemática de la racionalidad que ha estado vigente a lo largo de la historia del hombre, comenzando por la racionalidad fuerte: Mario Bunge (filósofo argentino), analizando los aportes de Herbert Simon y Daniel Kahneman (Premios Nobel), hasta llegar a la Teoría de la Racionalidad Instrumental Mínima (Elster, Pavesi.)

Distinguiremos también conceptos morales y éticos, mal hermanados a la racionalidad.

Plantearemos como reflexiones finales los preceptos de la teoría de la decisión y algunas críticas a la Teoría Mínima de la Racionalidad Instrumental Mínima, a partir de lo investigado y con el aporte variado de los autores seleccionados, brindando especial importancia a los aspectos débiles observados en dicha teoría.

Palabras claves: Racionalidad; Subjetividad; Decisión.

\section{Abstract}

The decision making is the process that more studies treasures and it also attracts more specialists in different areas, as economist, consultants, engineers, psychologists, doctors, neurologists, even cardiologists, all these experts contribute to improve this process that is omnipresent in our lives. We are concerned about analyzing in this process, the qualification of rational or irrational according to different currents of thought, within the framework of the Decision Theory.

We will tackle a bit of history and characterization of the problematic of rationality that has been in force throughout the history of mankind. Beginning with the strong rationality: Mario Bunge (Argentine philosopher, analyzing the contributions of Herbert Simon and Daniel Kahneman Nobel Prizes), until reaching the Minimum Instrumental Rationality Theory (Elster, Pavesi.)

We will also distinguish moral and ethical concepts, badly linked to rationality.

We will present as final reflections the precepts of the Decision Theory and some criticisms of the Minimum Instrumental Rationality Theory, based on what has been researched and with the varied contribution of the selected authors, giving special importance to the weak aspects observed in said theory.

Key words: Rationality; Subjectivity; Decision.
Patricia Bonatti

patricia.bonatti@fce.uba.ar

Facultad de Ciencias Económicas. Universidad de Buenos Aires. Argentina. 


\section{Introducción}

Los seres humanos tomamos decisiones en diferentes, variadas y complejas temáticas que abarcan nuestra vida cotidiana. Esta toma de decisión resulta ser un proceso deliberado, anterior a la acción y con proyección a futuro. Es así que cada individuo debe enfrentar dicho proceso según su propia percepción del mundo, sus propias creencias y su capacidad de raciocinio.

Buscamos la alternativa más eficaz y eficiente. Se torna relevante entonces comprender el proceso de toma de decisión, señalando fortalezas y sobre todo debilidades inherentes a dicho proceso. En este sentido, la toma de decisión representa un reto para muchas disciplinas, sobre todo para la Administración, ya que es su teoría más fuerte. La Teoría de la Decisión brinda herramientas que nos ayudan a mejorar el proceso, pero que no puede nunca garantizarnos el éxito, a causa de la incertidumbre del futuro al que debe enfrentarse. Nos asegura minimizar las posibilidades de fracaso, pero no elegir la alternativa que nos lleve a la máxima utilidad.

La toma de decisión es un proceso sistematizado que comienza con las decisiones previas (Meta decisiones) que son las decisivas para la elección última. Aquí se explicitan los fines, los valores, los propósitos de la decisión y las razones.

La racionalidad es un concepto fundamental en la filosofía y está presente en todos los asuntos humanos. Se identifica con la historia del pensamiento y en cada uno de sus períodos fue considerada de forma diferente.

El filósofo argentino Mario Bunge establece en su obra Racionalidad y Realismo (1985) conceptos muy duros al definir la racionalidad.

Comenzaremos con Aristóteles y Platón, pasando por el Racionalismo moderno de Descartes, hasta llegar a autores como Elster, Pavesi, Davidson, Morin, entre otros. Se confunden conceptos, se aplican desde la teoría misma que no refleja la práctica del accionar humano. El proceso decisorio se inicia con la explicitación de los fines perseguidos por el decisor. (Meta Decisiones). Y siempre existen "razones" para decidir. Es aquí donde se incorporan los valores éticos, los valores morales, las restricciones del decisor, su cultura, etc. Se debate la incorporación de los fines éticos. Ética y Racionalidad son claramente conceptos independientes, lo que implica una toma de posición en una discusión muy antigua. Las críticas apuntan a la no incorporación de los valores éticos. Se dice que nos lleva a una Ciencia no-valorativa.

En este ensayo responderemos estas preguntas planteando claramente la validez de la Teoría de la Racionalidad Instrumental Mínima.

\section{Desarrollo}

\section{Racionalidad}

Desde Aristóteles se debate el concepto de racionalidad como requisito de la verdad en primer lugar, pasando luego por la verdad sobrenatural, la racionalidad crítica, racionalidad limitada, etc. La Ética, nombre derivado de la voz griega que significa "costumbre", se aplica a la parte de la Filosofía que trata de las cuestiones relativas a los juicios morales. Poseer sabiduría, valor, templanza, justicia (las cuatro virtudes cardinales griegas) es vivir la aceptable vida ética.

Sócrates, tratando de inquirir las razones de las acciones humanas, revolucionó a la juventud de su tiempo revelándole cuán irracionales eran muchos de sus juicios morales y señalándole a la razón como verdadera guía de la vida moral.

Es notorio que desde los comienzos de la humanidad las razones, la ética y la moral fueron conceptos unidos por su relación causa-efecto. Aristóteles, por su parte, afirmaba con Platón que la vida buena halla expresión social, cívica y política y tiene su asiento en un mundo gobernado con arreglo a la razón.

Pero ¿cuál razón? ¿Qué es la racionalidad? La discusión gira alrededor de conceptos distintos, contradictorios y en muchos casos asimilando otros conceptos, que solo generan más confusión en el tema.

En la "Gran enciclopedia del Mundo" se define la racionalidad (1974): "Doctrina filosófica fundada en la omnipotencia de la razón, que tanto en filosofía como en teología se establece como último criterio de validez de la verdad" (p. 16-039). Se incorpora el concepto de verdad. ¿Cómo llegamos a la verdad?, ¿a través de los sentidos? ¿Qué tipo de evidencia se requiere? El Racionalismo clásico, representado por René Descartes, Gottfrie Wilhelm, von Leibniz y Baruch Spinoza en el S. XVII y luego con Kant en el S. $\mathrm{XVIII}$, consideraba al intelecto como fuente para el dominio del conocimiento procedente del mundo 
externo. Esto se encuentra en oposición al empirismo que se origina en hechos concretos.

El Racionalismo moderno de Descartes, Spinoza, con la Escuela de Frankfurt enuncia su racionalidad crítica. Se cuestiona el conocimiento sensorial y se dice que aquí no hay verdad, que toda la verdad se obtiene deductivamente de unas pocas ideas exclusivas de la propia mente, no sacadas de los sentidos. Para Spinoza el último criterio de la verdad es la mente misma. La mente no podrá errar, si erra es por influencia de la voluntad y basada en los juicios de los datos engañosos de los sentidos. El concepto aquí es que la verdad es estrictamente el producto de la razón, no de los sentidos.

El Racionalismo Kantiano vuelve a relacionar en forma recíproca los sentidos y el entendimiento. Desde Kant se sostuvo que ciertos aspectos del mundo no pertenecen a éste, sino que son propios de nuestro cerebro.

Isaac Newton con sus descubrimientos físicos en 1750 logró que las ciencias naturales alcanzaran el éxito: la racionalidad y el realismo se reconciliaron. En cambio, las ciencias sociales negaron la posibilidad de explicar lo social. Es aquí donde aún viven los debates sobre la racionalidadrealismo y la racionalidad-causalidad. Son las ciencias sociales y humanas que aún dan origen a los debates acerca de su status epistemológico, su práctica, su utilidad aplicada a la práctica.

Con el aporte del trabajo de los psicólogos, neurólogos, etc. se atesoran experiencias de las neurociencias que demuestran que nuestra percepción está condicionada fuertemente por las emociones y otros procesos neurológicos y biológicos.

Entonces el mundo percibido es un mundo subjetivo, vislumbrado por el propio decisor, y que siempre será un tanto diferente al Mundo Real, siempre estará teñido con matices distintivos propios del ser humano, significativos o no, relevantes o no, en su distancia al Mundo Real.

La pretendida y tan buscada objetividad no existe, es imposible de lograr por la propia condición subjetiva, emocional del decisor.

Los límites de la racionalidad son la preocupación central de la teoría administrativa porque es el límite entre los aspectos racionales y no racionales del comportamiento social humano.

Esta es la principal preocupación de las Ciencias Cognitivas. El mundo es lo que nos rodea, pero los seres humanos formamos parte de él e interactuamos con él. Ese mundo está teñido indefectiblemente por nuestras emociones, por el pasado, por la interpretación diferente de lo que "creemos" realidad, por nuestra subjetividad....

\section{Bunge, Mario}

Bunge, físico argentino, filósofo de la ciencia y humanista argentino, acérrimo defensor del realismo científico y de la filosofía exacta, escribe ya en 1985 su obra Racionalidad y Realismo. Afirma que existe un problema en torno a la palabra racionalidad, ya que designa por lo menos siete conceptos diferentes:

1) conceptual: minimizar la borrosidad (vaguedad e imprecisión);

2) lógica: bregar por la coherencia (evitar la contradicción);

3) metodológica: cuestionar (dudar y criticar) y justificar (exigir demostración o datos, favorables o desfavorables);

4) gnoseológica: valorar el apoyo empírico y evitar conjeturas incompatibles con el grueso del conocimiento científico y tecnológico;

5) ontológica: adoptar una concepción del mundo coherente y compatible con el grueso de la ciencia y de la tecnología del día;

6) evaluativa: bregar por metas que, además de ser alcanzables, vale la pena alcanzar;

7) práctica: adoptar medios que puedan ayudar a alcanzar las metas propuestas.

Para Bunge, los matemáticos y lógicos se especializan en los tres primeros tipos (las racionalidades conceptual, lógica y metodológica). Los científicos estudiosos de la realidad debieran respetar, además, las racionalidades gnoseológica y ontológica. Y los administradores, tecnólogos e individuos de acción prefieren las racionalidades evaluativa y práctica.

Este pensador recomienda el abordaje desde una perspectiva global, aclarando que, si se elige alguna de las racionalidades a expensas de las demás, resulta una racionalidad parcial. Y las doctrinas que no cumplen con todos estos conceptos son semi-racionales. Entre las cuales nombra a la teoría de la decisión.

Para Bunge, el mundo exterior es un lugar independiente de nuestra percepción y resulta cognoscible y transformable. Es digno representante del realismo científico, del positivismo. Con este 
realismo podremos tener la mejor representación de la realidad. Podemos, a diferencia del realismo ingenuo, adoptar convenciones, abstracciones y captar la acción con el plano teórico.

Bunge afirma que todos los individuos buscamos o utilizamos algunas verdades, y ocultamos o falseamos otras. Sin algunas verdades no podríamos sobrevivir $y$, si no fuésemos veraces, al menos en algunas ocasiones, no podríamos convivir. "Sólo los déspotas y los estafadores, así como los malos administradores, políticos y hombres de armas, ocultan o tergiversan sistemáticamente la verdad. Pero para ocultarla o tergiversarla tienen que empezar por conocerla" (Bunge, 1985, p. 27).

La racionalidad carece de valor si es que no se la acompaña de una búsqueda o utilización de la verdad. En relación a las verdades, la racionalidad teórica no es un fin sino un medio, un medio para alcanzar la verdad o hacer uso de ella. Para Bunge no hay una sola verdad, sino muchas verdades, tantas como conocimientos correctos.

Bunge, en relación a las verdades de razón, establece que son verdades que pueden establecerse con la sola ayuda de la razón. Es decir, no se requieren indagaciones empíricas. Asimismo, Bunge plantea la existencia de cinco diferentes clases de verdades de razón:

1) verdad de diccionario: como una definición nominal;

2) verdad a pedido o por postulación: como postulado de una teoría matemática;

3) verdad por demostración o deducción: como un teorema de una teoría;

4) verdad lógica: como cualquier fórmula válida de un sistema de lógica;

5) verdad por ejemplificación: como la que satisface un modelo.

De todas las verdades de razón anteriormente listadas, para Bunge sólo las dos últimas, la verdad lógica y la verdad por ejemplificación, son legítimas.

En adición a las verdades de razón, Bunge presenta las verdades de hecho. Estas últimas corresponden, como su nombre sugiere, a hechos, hipótesis u objetos concretos. En palabras de Bunge, cuando buscamos la verdad de hecho exigimos realismo. La verdad de hecho, contrastada con la verdad de razón, corresponde a la adecuación de la realidad y debe ser realizable.

Bunge, refiriéndose al realismo, enuncia que podemos decir de un relato o de una pintura, de una teoría o de un diseño técnico que son realistas o irrealistas en mayor o menor grado. Para Bunge es preciso entender la palabra realista como lo fiel a la realidad. No obstante, no siempre exigimos que nuestras creaciones se ajusten a la realidad.

Por otro lado, Bunge diferencia otro tipo de realismo, que es el denominado gnoseológico. Esta doctrina filosófica sostiene que el mundo existe de por sí y que los humanos podemos conocerlo, aunque sólo sea en parte y de a poco. Este realismo gnoseológico difiere del realismo metafísico, que sostiene que las ideas existen por sí mismas, de forma independiente de nuestros cerebros.

Existe una gran variedad de "teorías de la elección racional": teoría de las utilidades, la teoría de las decisiones y la teoría de los juegos, entre otras, cuyas hipótesis comunes, según Bunge (2005), son:

1) Utilidad y probabilidad: todo agente posee una función de utilidad (valor subjetivo) estable y puede asignarle una probabilidad subjetiva a cualquier evento (real o posible) que le interese.

2) Racionalidad: todos los sujetos son racionales porque actúan maximizando sus utilidades (simples o esperadas).

3) Individualismo ontológico: los grupos sociales no son más que colecciones de individuos.

4) Individualismo metodológico: las propiedades y los cambios de cualquier grupo social se pueden entender al estudiar el comportamiento de sus miembros.

Para analizar el "postulado de racionalidad", se recurre a conceptos alternativos como los siguientes:

1) Principio del comportamiento adaptable: los agentes actúan de manera apropiada según la situación en que se encuentren.

2) Principio de racionalidad instrumental: los agentes siempre adoptan los medios que produzcan con mayor probabilidad los resultados deseados.

3) Principio de racionalidad (económica): los agentes siempre actúan por interés propio para maximizar sus utilidades esperadas.

4) Principio del menor esfuerzo: los agentes escogen el medio menos caro para alcanzar sus metas.

5) Principio de la racionalidad subje- 
tiva: los actores siempre actúan en base a sus "creencias" acerca de sus circunstancias, los medios más aptos y las consecuencias posibles que sus acciones pueden acarrear para ellos mismos y para otros, y buscan las consecuencias que le parecen mejores.

Estos aportes, estos principios nos indican que la Racionalidad plena, perfecta es perfectamente aplicable a las Ciencias Naturales ("duras") y no a las Ciencias Sociales. Pretender asimilar estos conceptos a las Ciencias Sociales, tal es el objetivo del realismo (positivismo), transitar un camino que solo nos lleva a la imposibilidad de su aplicación en el comportamiento humano.

En el libro Intuición y Razón (1996) expone las controversias existentes con el término intuición y concluye que, una vez reconocida la debilidad de la intuición, ésta bloquea al razonamiento y este razonamiento equivocado debilita la intuición que puede ser valiosa.

Finalmente, en 1999 (Buscar la filosofía en las Ciencias Sociales) enuncia ciertos principios que responden al concepto de Racionalidad Instrumental. Estos son: la deliberación del sujeto, el tiempo dado, el medio efectivo, la información disponible, la prioridad de los objetivos y el costo involucrado.

Un número considerable de investigaciones que comenzaron con la psicología ya demostraron que la acción humana es poco predecible, por la subjetividad en la visión del mundo y en la definición de las meta decisiones que son únicas y propias del ser humano.

La Racionalidad en la Administración. La Teoría Amplia de la Racionalidad hasta la Racionalidad Instrumental Mínima

Nos interesa aplicar dichos conceptos al área de Administración, analizando su evolución desde la Revolución Industrial para llegar a los avances y aportes de otras disciplinas que avanzan con nuevos hallazgos, mayor conocimiento del comportamiento humano y que siembran todavía más dudas a la noción de racionalidad plena, racionalidad perfecta.

Con los estudios sistemáticos de Taylor y Fayol luego de la Revolución Industrial el modelo económico neoclásico era el de decisor como un agente racional. Este agente racional persigue como propósito la maximización de su utilidad, es decir, el hombre económico.

A partir del año 1947 (2da. Publicación del libro Teoría de los Juegos y el comportamiento económico), John von Neuman y Oskar Morgenstern darán nacimiento a la primera teoría normativa, con sus axiomas y teoremas. Revisada y completada luego por J. Savage, Allais, Herstein y Milnor, Luce y Raiffa, Jensen entre otros. Bajo ciertos axiomas que indican el comportamiento racional, el decisor enfrenta el riesgo (probabilidades) y los resultados de las diferentes alternativas siempre maximizando el valor de esos resultados futuros que son producto de su propia función de utilidad. Esa función es la función del "valor subjetivo" que el decisor atribuye a sus resultados monetarios. Esa función de valor es la base de toda la teoría de la utilidad esperada. Subyace aquí el concepto de racionalidad del agente económico que actúa con sus preferencias conocidas, definidas e invariables. Su objetivo se ajusta siempre a la maximización de la utilidad de sus resultados monetarios. Cualquier preferencia individual que viole los axiomas presentados (orden completo de las preferencias, transitividad, etc.) para estos autores son comportamientos irracionales.

Estos supuestos indican que el decisor conoce de antemano todas las alternativas que puede accionar y que siempre va a seleccionar la que le ofrezca la máxima utilidad. No se cuestiona la percepción del individuo, no se tiene en cuenta la emoción del ser humano, ni sus debilidades a la hora de fijar sus objetivos, su escala de preferencia. $Y$, si esto llegara a comprobarse, se dice que representa un comportamiento irracional. Es la manifestación de la racionalidad plena llevada al campo social. Es la idea del robot decisor, sin creencias previas, sin emoción, sin subjetividad y plenamente racional en sus preferencias y en su elección.

A comienzos de los años 70, cambia el escenario del mundo cuando entra en escena el fenómeno de la globalización, los mercados tradicionales comienzan a estancarse, surge el problema competitivo. Se comienzan a cuestionar los supuestos neoclásicos de la racionalidad del decisor.

\section{Simon, Herbert}

Herbert Simon (1916-2001), Premio Nobel en 
Ciencias Económicas en 1978, publicó en 1947 la primera edición del ComportamientoAdministrativo, que puede considerarse la obra paradigmática en la que se definen las principales características de las organizaciones formales y una conceptualización de la ciencia social Administración. Se describen los procesos ejecutivos, los principios fundamentales de la administración y presenta como proceso esencial al proceso decisorio.

En dos de sus capítulos (Capítulo IV y V) trata el concepto de racionalidad presentando su concepto de "racionalidad limitada".

...no debe interpretarse la concentración sobre los aspectos racionales del comportamiento humano como una afirmación de que los seres humanos son siempre o generalmente racionales. Este falso concepto, que impregnó la teoría política utilitaria y una gran parte de la teoría económica clásica, ha sido refutado de una manera decisiva por los desarrollos modernos de la psicología y de la sociología (Simon, 1947, p.59).

"Hablando en términos generales, la racionalidad se ocupa de la elección de alternativas preferidas de actividad de acuerdo con un sistema de valores cuyas consecuencias de comportamiento pueden ser valoradas" (Simon, 1947, p.73).

Si la conciencia se considera un elemento de la racionalidad, se pregunta: ¿se admiten únicamente los procesos deliberados de adaptación o se admiten también los no deliberados? ¿Cuándo es racional la conducta de un empleado dentro de una organización, cuando sirve a los objetivos organizacionales o cuando sirve a sus objetivos personales?

Por eso establece y distingue varios conceptos de racionalidad, utilizando la palabra racionalidad adicionada a los adjetivos:

1) Objetivo: si busca maximizar valores dados en una situación dada.

2) Subjetivo: si busca maximizar la consecuencia relativa al conocimiento real del sujeto.

3) Consciente: si la definición de los medios y fines fue la conclusión de un proceso consciente.

4) Deliberado: si la definición de los medios y fines fue realizada en forma deliberada por el sujeto o por la organización.

5) Organizativo: si los fines que se pretenden lograr son los organizacionales.

6) Personal: si los fines que se pretenden lograr son los personales.

Para Simon, entonces la racionalidad objetiva no existe y el comportamiento real se expresa de 3 maneras:

a) La racionalidad exige un conocimiento y anticipación completa de las consecuencias de cada alternativa. $Y$ este conocimiento es siempre parcial, fragmentario.

b) Las consecuencias de las alternativas son siempre futuras, y esto implica una imposibilidad de anticiparlas de manera perfecta.

c) La racionalidad exige una elección entre todas las alternativas posibles, y nunca podemos aseverar que estamos analizando todas las alternativas factibles en las decisiones.

¿Cuándo es un proceso lógico? Siguiendo a Simon, es lógico si el decisor puede expresar en palabras las razones que lo llevaron a elegir una alternativa. Y será no lógico si no puede expresar las razones que lo llevaron a dicha elección.

En esta primera edición se plantea la idea de la "racionalidad aproximada"; recién en la segunda edición, en 1957, plantea la noción de racionalidad limitada.

"Con frecuencia, el modelo del comportamiento humano está más próximo a un sistema de estímulorespuesta que a una elección entre alternativas. La racionalidad humana pues, opera dentro de los límites de un medio ambiente psicológico" (Simon, 1947, p.104)

En las ediciones siguientes (1957-19761997) fueron cambiando los modelos. Diez años después de la primera, Simon consideró la primera visión de racionalidad limitada como un esquema demasiado débil, rudimentario. En 1976 (veinte años después) reconoció que se había operado un renacimiento del interés por la racionalidad humana en psicología y que en ese momento era más factible armar un esquema de elección racional que en el año 1947. Y que ese modelo podía incorporar 
los avances en los estudios del comportamiento real de los seres humanos. Y agrega que había que hacer dos correcciones fundamentales para convertir al hombre económico en el hombre de racionalidad limitada:

1) Mientras que el hombre económico "maximiza" (elige la mejor alternativa de todas las que tiene al alcance), el hombre administrativo se conforma con...(busca un camino satisfactorio, lo bastante bueno).

2) El hombre económico trata con el "mundo real" en toda su complejidad. El hombre administrativo reconoce que el mundo que percibe está simplificado en relación al mundo real. El mundo real es muy confuso, muchos de esos hechos no tienen relación con lo que él enfrenta, por eso simplifica con las causas y consecuencias que sí son relevantes y éstas son breves y sencillas.

Es decir, las elecciones de los individuos no siempre son coherentes ni racionales (en el sentido de la racionalidad perfecta). De allí surge su racionalidad limitada y el concepto de "satisfacción" en lugar de la "maximización". La racionalidad intuitiva incorpora el juicio y la buena intención de los seres humanos. Los decisores se dan por satisfechos pues no pueden aspirar a conseguir el "máximo".

En el año 1989, Simon presenta el concepto de racionalidad olímpica y racionalidad intuitiva. La primera es algo irreal, pues el decisor no pude contar con el pleno dominio de las condiciones para decidir. No puede elaborar un mapa completo de alternativas para elegir el curso de acción que le cumpla con la función de utilidad.

Cada decisor enfrentado al proceso decisorio, que es siempre futuro, analizando ese mundo, obtendrá una visión particular, diferente. Será una aproximación, seguramente más simple, comparada con todo el mundo. Hará foco en algunas variables y usualmente con algunos o muchos errores.

En el año 1997, Simon en la nueva versión del libro expresa con claridad que la teoría administrativa es esencialmente la teoría de la racionalidad limitada e intencional pues los individuos en su comportamiento "satisfacen" en lugar de "maximizar" pues no cuentan con la inteligencia necesaria para ello.

Ese mismo año Simon edita el tercer volumen del libro Modelos de Racionalidad Limitada y define concretamente los conceptos de racionalidad y satisfacción con los mismos términos utilizados anteriormente. Precisó que era necesario distinguir la racionalidad global de la limitada.

En la Racionalidad Global -que responde a la idea de la teoría neoclásica- el proceso decisorio se basa en que el decisor tiene una función de utilidad, conoce todas las alternativas y sus consecuencias de implementación futuras, y puede decidir en base a su función de utilidad, maximizando el valor esperado. En otras palabras, tenemos al "robot decisor".

En la Racionalidad Limitada, a la luz de los conocimientos que se obtuvieron al analizar el comportamiento humano, se sabe que el proceso es imperfecto, incompleto, partiendo de la base de que los decisores tienen restricciones propias que afectan el conocimiento del mundo que los rodea, por lo que esto afecta en la definición de los fines, de los medios, de la propia función de utilidad. Hacemos mención a la psicología y a la sociología como ciencias que aportan al comportamiento humano.

Ya en el año 2000 (un año antes de su muerte) Simon escribe, a partir de una revisión del libro de Peter Alvin (Alvin, 1998), el completo fracaso de la teoría neoclásica, las nuevas complejidades de la economía, la nueva visión de la teoría del caos y de los modelos de inteligencia artificial, lo que lo lleva a afirmar que no existe un modelo único del comportamiento humano sino una serie completa de modelos.

Siguió remarcando el concepto de racionalidad limitada y destacó los avances de las investigaciones empíricas de los investigadores en psicología cognitiva aplicadas a la teoría de la decisión enfrentando la incertidumbre.

Se demuestra que Simon en sus escritos, aportes, discusiones, etc. fue considerando e incorporando los aportes de los psicólogos, de la psicología cognitiva experimental. Y hasta su muerte demostró no estar convencido de los términos que había utilizado en relación a la decisión, a la racionalidad, etc.

Ese mismo año publicó La Racionalidad Limitada en las Ciencias Sociales: Hoy y mañana, en el que volvió a resaltar la aplicabilidad de la teoría de la racionalidad limitada a las ciencias sociales.

Destacamos el análisis y la sistematización 
de la Teoría de la Racionalidad Limitada en cuatro aspectos que habrá que profundizar en:

a) Encontrar fenómenos empíricos

b) Construir teorías

c) Testear teorías

d) Analizar la incertidumbre, destacando el universo futuro, las reacciones de otros actores que influencian y en el sistema de preferencias del decisor

\section{Kahneman, Daniel y Tversky, Amos}

Los estudios psicológicos más importantes comenzaron en la Universidad hebrea de Jerusalén (1968/1969) con los investigadores israelíes Daniel Kahneman y Amos Tversky atacando las prescripciones de la Teoría de la Elección Racional y los axiomas de las teorías normativas. Así se fueron detallando y comprobando con experimentos de laboratorio las llamadas trampas o sesgos a la hora de decidir, que nos lleva a un mapa de racionalidad limitada. Kahneman (Premio Nobel de Economía en el año 2002) y sus colaboradores catalogaron esas trampas en contextos de riesgo e incertidumbre además de precisar funciones de comportamiento.

The Prospect Theory, de Kahneman y Tversky, pasaría a ser el centro de los estudios empíricos sobre la toma de decisiones, que está relacionada con el análisis del comportamiento en situaciones de riesgo e incertidumbre. La Cumulative Prospect Theory propone una teoría para describir la toma de decisiones reales. Tversky y Kahneman profundizarán y darán nuevas dimensiones a las ideas de racionalidad acotada, iniciada por Simon en su Cumulative Prospect Theory (CPT).

Lejos de haber demostrado la irracionalidad humana como han sugerido estudios superficiales, han tomado distancia de la noción no realista de racionalidad perfecta indicando las vías para construir modelos en base a racionalidad acotada (Kahneman, 2003).

En la actualidad la psicología entiende que el proceso de decisión está compuesto por dos sistemas de pensamiento: uno, el intuitivo y el otro, de razonamiento (Kahneman, 2012). El primero procesa los estímulos más rápido, con bajo esfuerzo y utilizando mecanismos heurísticos como el asociativo o relacional entre los objetos que están siendo analizados para tomar la decisión. El segundo queda para los cálculos conscientes, realizados con esfuerzo y aprendizaje. Esto da una mejor aproximación a determinar cómo deciden los seres humanos.

Para nosotros los hallazgos de Kahneman no anulan las teorías normativas sino que las complementan. El conocer los mecanismos que en general son intuitivos, quizás inconscientes, nos abre la oportunidad de nuestra propia reflexión para minimizar esos sesgos (parecería muy osado pretender anularlos) y así ir acercando el proceso a la pretendida objetividad.

El enfoque pretende conjugar en un modelo íntegro y sistémico, relacionado con la psicología, que sirva a la hora de decidir.

\section{Elster, Jon}

Nos encontramos con aportes destacados como los de Jon Elster, teórico social y político noruego dedicado a estudiar la filosofía de las ciencias sociales y la teoría de la elección racional.

Elster entiende que la acción racional es aquel tipo de acción relacionado con razones, las cuales comprenden tanto creencias como deseos.

Las tres condiciones básicas para la acción racional son: a) que las razones sean razones para la acción, b) que las razones sean de hecho la causa de esa acción para la cual son razones y c) que las razones sean las causa de esa acción de modo "correcto". Así caracteriza una "teoría estricta" de la racionalidad (Thin theory).

Incluye esta teoría como un mecanismo de explicación y lo considera como válido en cuanto a poder utilizarlo en el afán de comprender la realidad, el universo de decisión, y lo considera además como un mecanismo superador.

Para Elster la racionalidad plena no se logra alcanzar al momento de la decisión. Habla de una racionalidad imperfecta (1989), pues, para él, el decisor que persigue sus fines en general no los alcanza con el grado de efectividad que asegure la racionalidad plena, sin por esto ser irracional.

Para Elster la racionalidad es parte de la "teoría de la acción" donde la racionalidad es el vértice principal de un triángulo y los otros dos son las normas sociales y las emociones. (Figura Nro. 1)

Pero las condiciones de incertidumbre no aseguran los mejores resultados de una acción. Por eso tiene un carácter instrumental: la decisión va en camino del mejor resultado esperado en la acción.

Para Elster, la teoría de la elección racional 


\section{NORMAS SOCIALES}

\section{RACIONALIDAD}

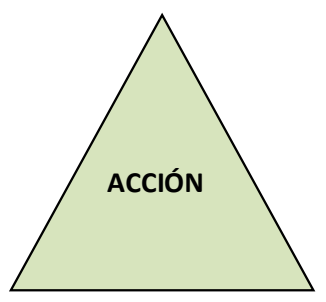

\section{EMOCIONES}

puede ser vista como normativa o prescriptiva. Como teoría normativa, nos indica cómo debemos proceder para alcanzar ciertas metas lo mejor posible, aún sin saber cuáles han de ser esas metas. Como teoría prescriptiva, nos brinda el soporte para predecir determinadas acciones.

En pocas palabras, los individuos realizan lo que creen que es probable que brinde el mejor resultado. Es aquí que la teoría muestra su carácter instrumental. Es decir, que se encuentra guiado por el resultado esperado de la acción.

El Planteo de la racionalidad en las Ciencias Sociales se hace desde el individualismo metodológico, que considera posible la explicación de la acción humana individual. En la "teoría de la elección racional" muestra que a) las personas maximizan su función de utilidad y b) las pautas sociales surgen como resultado de las interacciones de los agentes maximizadores.

La teoría de la elección racional ofrece una descripción de la conducta humana sólo si se cumplen los supuestos establecidos. Así, se recurre a los siguientes tres supuestos necesarios para garantizar que se dé una situación de elección:

1) un grupo de cursos de acción factibles que satisfagan ciertas restricciones lógicas, físicas y económicas;

2) un grupo de creencias racionales sobre la estructura causal de la situación que va a determinar qué cursos de acción nos llevan a qué resultados, y

3) un ordenamiento subjetivo de las alternativas factibles que se derivan del ordenamiento de las consecuencias a las que se quiere llegar.

Figura Nro. 2: Elección óptima Fuente: Elster (1989)

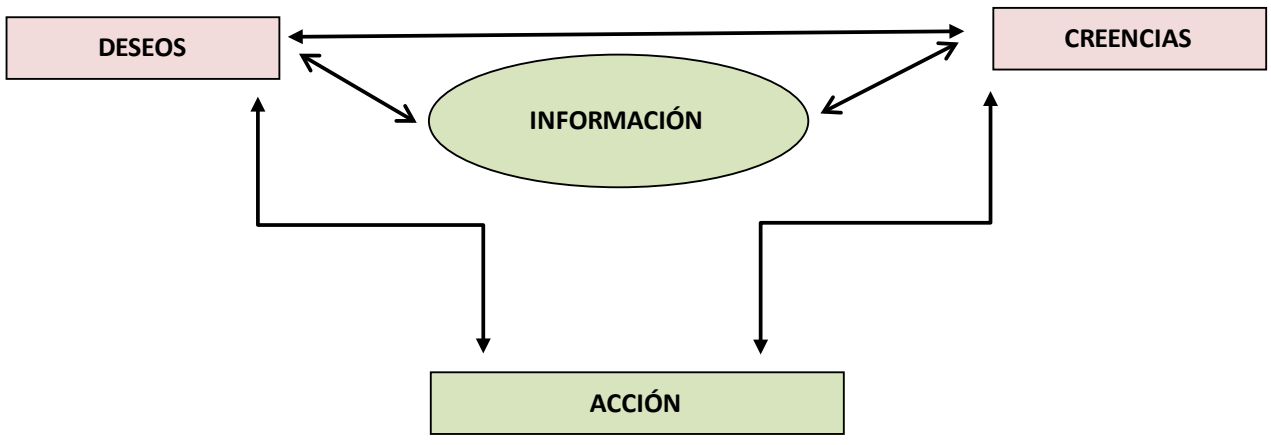


Para Elster, actuar de manera racional implica elegir aquella alternativa con la jerarquía más alta dentro del grupo de alternativas factibles y divide la situación de elección en dos dimensiones: deseos y creencias.

Elster explica que muchas de nuestras decisiones provienen de preferencias irracionales presentes en nuestra vida cotidiana. La forma en que los individuos moldeamos nuestras creencias y preferencias depende de las restricciones impuestas por el contexto y la propia situación. Como consecuencia, al considerar que el actor está condicionado por excepciones y desviaciones, surge la teoría del autocontrol como una forma de "teoría de racionalidad imperfecta".

Para Elster, la elección racional es instrumental, en el sentido de que se encuentra guiada por el resultado de la acción. Las acciones son evaluadas y elegidas no por sí mismas, sino como un medio más o menos eficiente para otro fin. Si bien la acción racional es instrumental, algunas formas de acción instrumental resultan irracionales.

Elster afirma que la elección racional se ocupa de hallar el mejor medio para fines dados. Se trata de una forma de adaptarse de manera óptima a las circunstancias. Es importante señalar que la elección racional no es un mecanismo infalible puesto que el individuo racional puede elegir sólo lo que cree que es el mejor medio. Por tanto, se pueden perder algunas oportunidades o no acertar por error.

Debemos requerir no sólo que las creencias sean racionales en relación a las pruebas disponibles, sino que además la cantidad de pruebas reunidas sea óptima en cierto sentido. Resulta probable que una decisión sea mejor frente a otra en la medida en que se reúnan más pruebas. No obstante, existe el riesgo de reunir muy pocas pruebas y, por otra parte, el riesgo de reunir demasiadas pruebas (lo cual puede devenir en pérdida de tiempo y por ende resultar contraproducente).

Resulta muy interesante y explicativo repasar sus aportes al análisis de las acciones humanas que parecen "irracionales". A estas situaciones les dedica Elster sucesivas obras.

Existen debilidades individuales y del marco decisorio que son las culpables de no poder alcanzar esa racionalidad plena. La subjetividad, entonces, no impide ser racional pues el concepto de racionalidad es completamente subjetivo.

a) Debilidad en la voluntad. ¿Es irracio- nal reconocer las propias debilidades en la voluntad?

En Ulises y las sirenas. Estudios sobre racionalidad e irracionalidad (1979), ofrece el relato de Homero con el canto de las sirenas:

Plena racionalidad: si los cantos de las sirenas le fueran indiferentes (luego del mecanismo instalado).

Irracionalidad: desconocer su debilidad y caer seducido y apartado de su senda.

El individuo siempre decide sus fines, sus objetivos. No es irracional reconocer debilidades en la voluntad. Es racional valerse de trucos para neutralizar esa debilidad.

b) Racionalidad Indeterminada. ¿Es irracional que el ser humano no pueda seleccionar la alternativa que maximice su utilidad?

Según Elster, sería una racionalidad indeterminada, no irracional, y esta situación puede deberse a:

- Incertidumbre. No pueden evaluarse los cursos de acción por falta de información.

- Interacción estratégica. Aquí intervienen otros actores que están influenciando la decisión. Ej.: teoría de los Juegos. Según Elster, "no hay modo en que un jugador pueda formarse una creencia racional de lo que hará el otro" (1999, p. 21).

- Imposibilidad de priorizar las preferencias. A nuestro juicio, el más frecuente.

c) Irracionalidad de las preferencias. ¿Es irracional la emoción racional basada en una creencia irracional?

En Uvas amargas. Estudios sobre la subversión de la racionalidad (1988), utiliza la fábula de la zorra y las uvas. La zorra se ve imposibilitada de alcanzar las uvas para satisfacer su hambre, uvas que están a punto justo, entonces el animal habilita un mecanismo inconsciente que lo protege que hace que vea a las uvas incomibles (estas uvas 


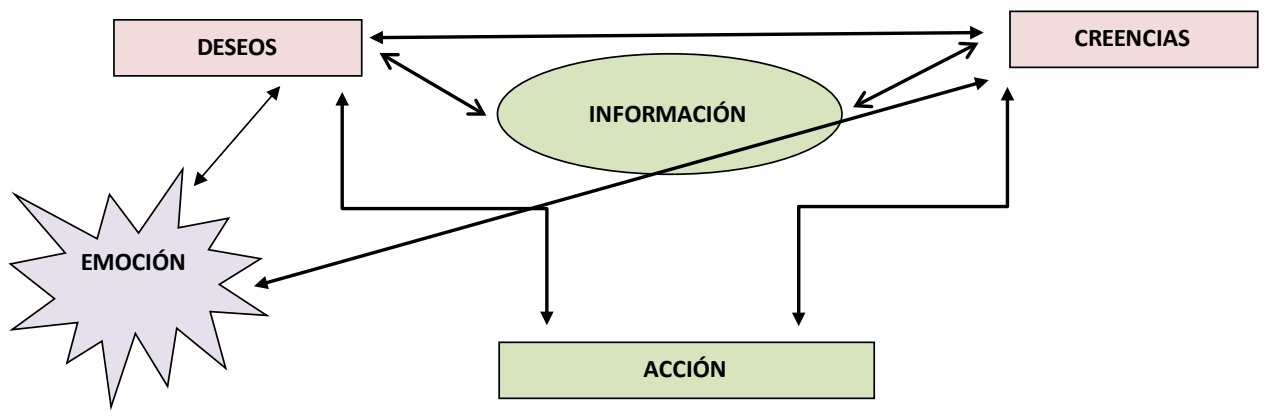

están verdes...). Este mecanismo ayuda a la zorra, la protege ante la frustración de no poder cumplir con su objetivo.

Aquí incorpora las emociones y sostiene que pueden ser apropiadas o adecuadas siempre en función a las creencias que las provocan. De aquí se desprende que puede darse el caso de una emoción racional basada en creencias irracionales y/o una emoción irracional basada en una creencia racional.

Elster se vuelve más escéptico respecto de poder explicar la "teoría de la elección racional" en la conducta humana y por eso incorpora las emociones al cuadro de la figura 3.

Algunos científicos insisten que es posible dar pautas para la explicación de la acción humana; para Elster en cambio, el decisor no siempre actúa por motivos "racionales" en sus decisiones.

\section{Pavesi, Pedro F.J.}

Pedro J. Pavesi, Doctor de las Ciencias Económicas de la Universidad de Buenos Aires, académico notable, estudioso de la Teoría de la Decisión, en su trabajo "Esbozo de una Teoría Mínima de la Racionalidad Instrumental Mínima" presentado en la VIII Jornadas de Epistemología de las Ciencias Económicas en la Facultad de Ciencias Económicas de la UBA (1997), sostiene que quiere sentar las bases para una teoría de la racionalidad menos exigente que la racionalidad mínima que propone Cherniak (1986) o la racionalidad débil de Elster (1988), hasta tanto exista una teoría de la racionalidad mínima o no; débil o fuerte pero reconocida por la comunidad científica para ser considerada apta para la conducta racional en el ámbito de la administración de organizaciones.

Su Teoría de la Racionalidad Mínima enuncia que la elección de un curso de acción será racional si el decisor llega a esa conclusión luego de un proceso de deliberación, de reflexión. El decisor tiene libertad de elegir sus fines y luego los medios que lo conducirán al cumplimiento mejor de esos fines enunciados.

Es una racionalidad instrumental referida a los medios y fines. La racionalidad abarca los diferentes elementos que conducen a la elección, que se pueden resumir en las expresiones de "deseos y creencias". Toda decisión implica deseos y creencias. Los deseos y creencias son subjetivos y pueden cambiar a lo largo del tiempo. Las creencias pueden ser racionales, pero existe una discusión acerca de si los deseos pueden ser racionales o no. Para el caso del enfoque normativo de la racionalidad, se exige que como mínimo el decisor ordene sus deseos por su importancia, llegándose a exigir que dicha importancia pueda medirse respecto a una escala racional. Los humanos actuamos con al menos un mínimo de reflexión acerca de la situación en la cual se toma la decisión. La reflexión es la condición única y necesaria para definir la racionalidad. No obstante, la capacidad de reflexión puede no ser suficiente para llegar a una elección. Se pueden producir problemas de sesgos, límites, capacidad, etc.

El decisor va cambiando en el tiempo, así como también sus fines, valores, evaluaciones y criterios. En este punto se plantea la problemática de con qué frecuencia puede cambiar sin que el sujeto deje de ser racional. Para Pavesi, mientras 
esa inestabilidad no sea patológica, es racional.

Por otra parte, Pavesi se refiere a la subjetividad del acto y sostiene que la racionalidad es esencialmente subjetiva. Todos los elementos que contribuyen a la elección racional dependen de la información, percepción, evaluación, interpretación, sentimientos del actor y de sus circunstancias. El actor elegirá la decisión que más prefiere en su apreciación de los elementos de la situación.

Lo importante es que los fines son propios del sujeto. Pavesi también sostiene que los fines no son objeto de la racionalidad instrumental. La problemática de la racionalidad de los fines es que éstos, por lo general, conllevan a varios objetivos últimos. La sutileza de la racionalidad de los fines consiste en que cuanto mayor sea la jerarquía del objetivo, más difícil es emplear el raciocinio para analizarlos. El determinismo causal no es admitido en el esbozo de la teoría que plantea Pavesi.

En adición, existe un precepto que aparece en el estudio de la racionalidad que es el de la universalidad. Para Pavesi este precepto no es aplicable, ya que no todos los sujetos racionales en posesión de la misma información llegan a la misma elección. Es por ello que dicho principio no forma parte de la teoría.

Finalmente, para Pavesi toda elección deliberada es racional. Observamos que, a pesar de que la racionalidad es comúnmente vista desde el aspecto normativo, lo expuesto anteriormente es descriptivo de la relación de intencionalidad de la elección deliberada en la cadena fines - medios situación - elección.

Toda elección - acción humana deliberada es racional. Esto quiere decir que con la deliberación la decisión - acción humana es válida. Parte de nuestra naturaleza humana es precisamente el uso del pensamiento, de la reflexión y de la deliberación. Y siempre perseguimos lo que preferimos. "No hay second best ni suboptimización ni akrasía: siempre se optimiza, aun cuando el actor no se dé cuenta y el observador no concuerde". (1998, p.6)

El ser humano con su propia y única estructura mental, con sus sentidos y las ilusiones cognitivas propias y del contexto, hace lo mejor que puede: tratar de accionar la alternativa elegida para cumplir con sus fines, sus objetivos.

El decisor no puede abarcar todo el universo en cuestión, como así también no puede jamás estar con la certeza de poder analizar el mundo real, siempre habrá distorsiones, mínimas o máximas, siempre estará aumentado o disminuido en intensidad, en variables, en relaciones, etc., que provengan de su emoción, de su propio intelecto y razonamiento conjugándose con los del contexto referencial.

Hasta aquí hemos desarrollado los conceptos aplicados a un decisor, a una sola persona actuando en una decisión personal.

Los objetivos de cada decisión son libremente definidos y perseguidos por los que accionarán la alternativa elegida, los decisores en cuestión, en las Meta Decisiones.

En relación a las "conductas irracionales" y más precisamente a la debilidad de voluntad o incontinencia, para Pavesi no existe ni forma parte de su teoría. Se trata de una extraña actitud, afirma. No existe más allá de la razón consciente, una razón inconsciente más fuerte. La preferencia es íntima y la elección es pública, una declaración de preferencia es coherente con la elección y viceversa.

Para estos autores, entonces, la Racionalidad objetiva, plena, no existe en las Ciencias Sociales: Simon, Elster, Kahneman, entre otros. La racionalidad es así, esencialmente subjetiva y nada más que subjetiva.

\section{Algunas reflexiones finales}

Bunge aboga por un sistema de racionalidad global en el que la racionalidad teórica (conceptual, lógica, metodológica, gnoseológica y ontológica) es un medio para alcanzar la verdad, los fines o hacer buen uso de ellos. Sólo aceptará una teoría de la decisión racional y objetiva, que pueda ampliarse en las condiciones de incertidumbre. No acepta las probabilidades subjetivas y enuncia que no se llegará a la categoría de ciencia mientras que se sigan aceptando las probabilidades subjetivas. Sólo tienen validez las probabilidades objetivas y los soportes o evidencias empíricos.

Bunge afirma que es semi-racional la doctrina que satisface algunas racionalidades, pero no todas; que es plenamente racional aquella que satisface todas; y que es irracional la que rechaza a todas.

Por lo anterior, para Bunge la plena racionalidad parece ser inalcanzable. Es por ello que para el filósofo la plena racionalidad es un "desiderátum teórico y práctico", es decir, es complejo de lograr.

Esta perspectiva muestra que la mayoría 
de las acciones estarían dentro de lo semi-racional. Una debilidad significativa que está presente en la teoría de Bunge es que ésta carece de un factor muy importante en materia del comportamiento humano, el factor psicológico, en donde están las características internas del individuo, por ejemplo, las emociones.

Elster, refiriéndose a la elección racional, hace hincapié en que la elección racional no es un mecanismo infalible, ya que el individuo racional puede elegir sólo lo que él cree que es el mejor medio y ello generaría la pérdida de oportunidades (o no acertar por error).

Elster expone la Teoría amplia de la racionalidad en la que admite el papel significativo que tienen las emociones. Hay tres motivaciones que regulan la conducta humana: la racionalidad instrumental, las normas sociales y las emociones. Acepta la racionalidad subjetiva y enuncia la teoría de la racionalidad imperfecta, el reconocer el rol de las preferencias y creencias del agente. En sus aportes, se puede observar otra debilidad en la teoría. Ocurre que los seres humanos no siempre somos seres racionales en nuestro comportamiento, también hay ocasiones en las que no actuamos o no nos comportamos de manera racional. Entonces, es posible esquivar el concepto de la racionalidad en los diferentes pasos del proceso: en la acción, en la formación de las creencias, etc.

Una postura más conciliadora, teniendo en cuenta los avances de otras disciplinas y más aplicable a la realidad circundante, es la denominada teoría de la Racionalidad Instrumental Mínima (Pavesi). Esta teoría tiene en común con la teoría amplia de Elster que los objetivos, propósitos de toda situación de decisión son definidos por el decisor y no se imponen objetivos de orden ético, político o social. Ambas teorías entienden que la ética es trascendental y que toda expresión de objetivos es racional si existe una deliberación previa para su fijación. Cada decisor tendrá "sus razones". Da lugar a la desobediencia. El decisor puede tener objetivos éticos y objetivos no éticos. Será su propia ética, moral, etc., que le impondrá sus valores, y no la teoría en sí misma.

Existen excepciones y desviaciones que pueden afectar y alterar el curso de esta teoría. La irracionalidad que está presente en nuestro día a día se pone de manifiesto en los casos de falta o debilidad de voluntad, exceso de voluntad, preferencias adaptativas, etc.

Asimismo, la teoría que plantea Elster también descuida que gran parte de nuestro comportamiento viene influenciado por nuestros hábitos, costumbres y normas sociales. Esto también afecta la forma en que tomamos decisiones.

Para Pedro Pavesi, la teoría de racionalidad instrumental ofrece una gran amplitud y su única restricción se ubica concentrada en la reflexión misma. Esta reflexión (deliberación, raciocinio, análisis) resulta suficiente para definir la racionalidad. Afirmamos entonces que "toda elección deliberada es racional" (1997, p.13). Con lo cual, el calificativo "racional" se suele confundir con el de "deliberado". Es importante que se comprenda que la teoría, en este caso, busca centrarse en la utilidad que alcanza el proceso mental de la reflexión.

\section{Algunas reflexiones sobre la Ética en las Meta Decisiones}

En el marco de la Administración, y más precisamente en Teoría de la Decisión, se debaten los aspectos éticos de las decisiones. Uno de los temas que suele atravesar las reflexiones y debates sobre la teoría de la decisión es el referido a los valores éticos que no forman parte de la teoría. Existen opiniones y creencias opuestas. ¿Es legítimo que la Teoría de la Decisión incorpore esos valores? ¿La Teoría de la Racionalidad Instrumental Mínima es tan mínima que es trivial? ¿Casi inexistente? ¿Es anti-ética?

Las teorías clásicas de la racionalidad plantean la diferencia entre las "cuestiones de hecho" y las "cuestiones de valor". Esta distinción implica que las cuestiones de hecho pueden ser ratificadas o refutadas racionalmente mientras que las cuestiones de valor son subjetivas. Y aquí se abre el debate ya que hay enfoques que precisan que en las cuestiones de valor debe también aplicarse la racionalidad.

Pareciera que surge la necesidad de la consideración de la ética imponiendo determinados fines a los decisores. Se restringe la libertad.

¿Pero qué sucede cuando nos encontramos en una organización? Es aquí donde varios estudiosos hablan de la racionalidad ética, conjugando voluntades individuales de acuerdo a los valores y objetivos de la organización.

Es otra confusión, en una organización partimos de objetivos generales que van convirtiéndose a medios en niveles inferiores. Por supuesto que debe existir aceptación de los fines 
organizacionales. Si no la hubiere, el agente decidirá en función a otros objetivos que no representen su preferencia y más pronto que tarde esto derivará en una frustración del agente o un abandono de esa organización. Esta es la mayor causa de cambios laborales.

La más común y quizás más perjudicial confusión es utilizar la palabra racionalidad como sinónimo de la ética. Desde la filosofía algunos sostienen que toda racionalidad debe ser ética (Adorno y Max Horkheimer, entre otros; la racionalidad discursiva de Jürgen Habermas etc.). Señalan como crítica más importante a la Teoría de la Racionalidad Instrumental Mínima la ausencia de los valores éticos. ${ }^{1}$

Karl-Otto Apel con su ética del discurso afirma que la racionalidad está en crisis porque se la ha reducido a una racionalidad puramente instrumental, cuyo caso extremo y más notable es el de la racionalidad científico-tecnológica. Este autor sostiene que considerar valorativamente neutra la racionalidad instrumental imputada a la ciencia tiene como consecuencia la obsolescencia de la racionalidad ética. Esto se debe a que toda discusión acerca de valores y normas para la acción ha sido dejada de lado (Apel, 1991)

Se plantea que la reducción de la racionalidad a su dimensión instrumental impide poner en discusión los fines y valores que guían las acciones de los decisores. La racionalidad instrumental, valorativamente neutra, no es suficiente. Se necesitan acuerdos de fines y medios que sean compartidos por la comunidad, con una reflexión crítica y permanente. Se considera a la teoría de la racionalidad instrumental mínima como insuficiente, hay que explicitar los valores.

"Esta no es nuestra posición: el sujeto tendrá o no tendrá en cuenta postulados éticos y morales de acuerdo a su personalidad o a su particular visión del mundo. Ética y Racionalidad son conceptos totalmente independientes" (Bonatti, 2011,p.38).

La ética es trascendental pero los fines son del individuo. El ser humano tiene la libertad de desobedecer, de mentir, de lograr el mejor provecho en aras de otro decisor o de la sociedad.

Una organización, una empresa, una entidad de bien público, la comunidad, la sociedad en la que actuamos puede y "debe" imponer fines éticos, pero no una metodología que nos ayuda a la hora de decidir.

Estamos de acuerdo en que en toda organización, toda comunidad, etc. la libertad de uno termina donde comienza la libertad del otro, por lo tanto esos fines tendrán que ser discutidos entre los sujetos a los efectos de llegar a un acuerdo, a fines compartidos y con valores incluidos.

Para algunos pensadores no existen métodos o instrumentos "a-valorativos". La Teoría de la Decisión no impone los fines. No incluye valores.

Los marcos perceptivos son estrechos, incompletos, únicos, sesgados. Es la racionalidad intrínseca de las conductas. Existen decisiones de mentir.

Si analizamos comportamientos humanos en la historia, considerando las relaciones mediosfines y costo-beneficio, se nos hará evidente que cada conducta resulta comprensible e indiscutiblemente "racional". Aunque ello haya significado mentir descaradamente, dilapidar dinero o comprometer imagen. Cada uno fue perfectamente racional y estaba orientado a cumplir otros fines, a preservar sus puestos, su dignidad personal, el reconocimiento de los pares, a preservar el poder, etc.

Dentro de la historia, todas las conductas adquieren pleno sentido. Solo fuera de la historia advertimos esas estafas, corrupción, comportamientos anti-éticos, etc. con el lente del observador que es diferente al del actor. Entonces cambiamos los valores, los fines, y si cambiamos los valores y/o los fines se trata de otra decisión.

Tenemos inhabilidad para ampliar el horizonte decisorio y/o considerar activos intangibles. Una variación en el horizonte decisorio puede modificar sustancialmente la decisión.

Padecemos las influencias de las rutinas y reglas. Marcos perceptivos de las jerarquías de la organización. Marcos perceptivos de la comunidad.

A veces la decisión no tiene fines intrínsecamente antiéticos per se pero pueden tener consecuencias antiéticas y ello no porque los involucrados fueran personas malvadas, deshonestas o incompetentes. Pueden ir cerrándose a la percepción de los aspectos éticos como consecuencia de marcos perceptivos estrechos y/o potenciados por factores de contexto.

No es la idea de exonerar de culpa o responsabilidad a los decisores en general, solo reflexionar en la posibilidad de que esto suceda. Lo

\footnotetext{
1. Horkheimer, Adorno y Jürgen Habermas fueron los mejores representantes del pensamiento crítico-negativo del siglo XX.
} 
que suele llamarse ceguera ética.

La ceguera ética describe una situación en la cual el decisor pierde la habilidad de percibir las dimensiones éticas del caso y, por ende, resulta altamente vulnerable al riesgo de incurrir en conductas moralmente reprobables. No estamos aprobando estas conductas, solo mencionamos que existen, que forman parte del acervo diario.

El decisor es libre para elegir, aún condicionado por muchas restricciones. El decisor define y decide cuáles son sus propósitos, sus fines, cuáles serán sus alternativas a implementar, de su horizonte de decisión (meta decisiones). Y es aquí donde incluirá o no sus valores éticos, su propia visión del mundo que lo rodea. El decisor tiene suficientes grados de libertad como para vacilar, dudar, angustiarse y finalmente elegir.

\section{Conclusiones}

Nos centramos, en primer lugar, en la contribución del filósofo argentino Mario Bunge, como mejor exponente del realismo y positivismo, eximio estudioso de la racionalidad, analizando su racionalidad plena, global, y sus distintos tipos de racionalidad. En la Era moderna aparecen diversas teorías de la elección racional entre las cuales se encuentra la Teoría de la Decisión. Más precisamente las Meta Decisiones que dan inicio al proceso decisorio, donde el sujeto define sus objetivos, producto de sus fines, deseos, creencias, emociones, etc.

Analizamos detalladamente los aportes de Herbert Simon, que consideramos el autor clave, brillante estudioso y obsesionado (en sus propias palabras) con el proceso decisorio y la racionalidad, quien más trabajó con el proceso de decisión relacionándolo con la racionalidad, quien planteó el fracaso de la idea del "robot decisor" de la teoría neoclásica llegando a la racionalidad limitada.

Mencionamos los hallazgos de los trabajos de los psicólogos en el proceso decisorio que abrieron una nueva perspectiva, el Premio Nobel Daniel Kahneman y su compañero Tversky. Analizamos en forma detallada la Teoría de la Racionalidad Instrumental Mínima, base de la Teoría de la Decisión, con los aportes de la Teoría amplia de Elster y la Teoría Mínima de Pavesi para detallar la postura de la Teoría de la Decisión que utilizamos en los abordajes del proceso decisorio. Una de las principales críticas a las teorías mínimas de racionalidad instrumental mínima es que resultan ser triviales. Es decir, son criticadas por ser mínimas, pobres. No obstante, si bien son mínimas, nos permiten comprender la realidad. En todo caso es la propia realidad la merecedora de la calificación de trivial. Es cierto que la única restricción que se impone es la reflexión, y eso la hace aparecer demasiado débil, casi trivial. Pero estamos convencidos que eso sucede en la realidad, que nos basamos en la libertad del ser humano, en su libertad de desobedecer.

Para nosotros, individuos, no hay varias racionalidades, sino que existe una sola racionalidad, un solo raciocinio. Se habla de la racionalidad para la decisión y acción. Por tanto, es una racionalidad instrumental. Un instrumento para obtener fines.

Tenemos una postura en relación al significado de racionalidad que resulta ser más práctica y simple que la de otros autores, puesto que la finalidad es encaminarnos hacia el proceso de toma de decisión individual. No hay nada más irracional que hablar de la racionalidad. El hablar de racionalidad generará imágenes distorsionadas.

La teoría instrumental mínima requiere una cierta deliberación para considerar una decisión "racional", por lo tanto no interviene en la definición de los fines, acepta su subjetividad, y por ende pueden ser no éticos. Por lo tanto, podemos ser racionales y éticos y racionales no éticos. $Y$ seremos racionales siempre y cuando hayamos tenido un mínimo de deliberación. Distinguimos taxativamente los ámbitos de la racionalidad y de la ética. Como dice Elster, la bondad ética no puede ser un criterio para definir la racionalidad de los deseos, creencias y decisiones.

Si bien la excesiva orientación a los resultados económicos y operativos que debe considerar el decisor y la presión para lograr esos fines entran en conflicto con la valoración ética, analizaremos su viabilidad en el contexto de los mundos esquivos y rebeldes. No nos centramos en las decisiones operativas reguladas por protocolos, normas que en general son del mundo dócil (certeza) ya que queda aquí excluida la reflexión ética. En general, en estos casos rigen las normas legales inherentes a la institución/organización de que se trate.

Vamos desarrollando nuestros propios mapas cognitivos, nuestros propios procedimientos para adentrarnos en la complejidad que debemos enfrentar, y así vamos navegando en ese mundo, mundo que no es objetivo. Así simplificamos el 
proceso de decisión y seguimos avanzando hasta elegir la alternativa y convertirla en acción. Pero ese proceso está teñido de nuestra propia subjetividad, no solo en la determinación de los fines y medios sino en la descripción de las variables que forman parte del mismo, a través de nuestro propio lente, individual y subjetivo. Tenemos limitaciones, hacemos foco en lo que nos emociona, en lo que más nos interesa, y una única delimitada decisión se ve diferente según sea el decisor involucrado. Entonces estaremos en presencia de marcos perceptivos que condicionarán la percepción "objetiva" que en realidad es un fenómeno de laboratorio y no una descripción del mundo que nos rodea. Debemos comenzar el abordaje al proceso decisorio siendo cuidadosos de los sesgos que actúan silenciosamente en nuestra mente y que nos distorsionan la realidad, a causa de nuestra emoción, de nuestra propia subjetividad como seres humanos. Si conformamos un equipo decisorio, debemos tener muy presente los riesgos de conformidad propios de las decisiones grupales, entre otras trampas. Debemos hacer el esfuerzo intelectual de minimizar su presencia perjudicial al abordar las Meta Decisiones de las cuales derivará la elección final.

Los seres humanos filtramos el mundo a través de nuestros sentidos primero y luego a través de nuestra mente que está compuesta por nuestra estructura genética, cultural, nuestro pasado, nuestras experiencias únicas y que nos definen con nuestra personalidad, nuestro carácter, nuestras emociones, y por último y no menos importante los marcos del entorno. Debemos reflexionar sobre nuestras limitaciones, ejercitarnos en el rol del abogado del diablo, añadir los consejos y las miradas de otros decisores involucrados, animarnos a cuestionar, sobre todo a los procedimientos standard, a las rutinas automáticas cotidianas que no hacen más que estrecharnos los marcos. Debemos buscar las señales de alarma que a veces sentimos y no profundizamos por el objetivo inconsciente de nuestra mente de simplificación, que estará siempre presente.

\section{Referencias Bibliográficas}

Apel, K.-O. (1991). Teoría de la verdad y ética del discurso. Barcelona: Paidós.

Alvin, P. (1998) Barriers and Bound to Rationality:
Essays on Economic Complexity and Dynamics in Interactive Systems. Duncan K. Foley, Princeton, NJ: Princeton University Press

Bonatti, P. (Coord.) (2011). Teoría de la Decisión. Buenos Aires: Pearson- Prentice Hall.

Bunge, M. (1985). Racionalidad y Realismo. Madrid: Alianza Editorial. S.A.

Bunge, M. (1996). Intuición y razón. Buenos Aires: Editorial Sudamericana.

Bunge, M. (1999). Buscar la filosofía en las Ciencias Sociales. Buenos Aires: Siglo XXI Editores Argentina S.A.

Bunge, M. (2005). Buscar la filosofía en las ciencias sociales. México: Siglo XXI Editores.

Cherniak, C. (1986). Minimal Rationality. Cambridge: MIT Press.

Durvan S.A. (1974) Gran Enciclopedia del mundo. España: Durvan S.A.

Elster, J. (1988) Uvas amargas. Sobre la subversión de la racionalidad. Barcelona: Editorial Península.

Elster, J (1989). Ulises y las sirenas. Estudios sobre racionalidad e irracionalidad. México: Fondo de Cultura Económica.

Elster, J. (1999). Juicios salomónicos. Las limitaciones de la racionalidad como principio de decisión. Madrid: Gedisa.

Habermas, J. (1990). Teoría de la acción comunicativa. Buenos Aires: Taurus. (Trabajo original publicado en 1981).

Horkheimer, M y Adorno, T. W. (2016). La dialéctica de la ilustración. España: Ed. Trotta S.A.

Kahneman, D. (2003). Maps of bounded rationality: Psychology for behavioral economics. The American Economic Review, 93(5), 14491475.

Kahneman, D. (2012). Pensar rápido, pensar 
despacio. Buenos Aires: Debate.

Pavesi, P.F.J (1997). Esbozo de una Teoría Mínima de la Racionalidad Instrumental Mínima. Trabajo presentado en las III Jornadas de Epistemología de las Ciencias Económicas, FCE-UBA, Buenos Aires.

Pavesi, P.F.J. (1998). Bunge y las Teorías de la Elección Racional: Una discusión. Trabajo presentado a las IV Jornadas de Epistemología de las Ciencias Económicas, FCE-UBA.

Simon, H. (1947). El comportamiento Administrativo. España: Aguilar.

Simon, H. (1957). El comportamiento administrativo. España: Aguilar

Simon, H. (1989). Naturaleza y límites de la razón humana. México: Fondo de Cultura Económica.

Simon, H. (1997a). Administrative Behaviour (4은 Ed.). New York: Simon \& Schuster Inc.

Simon, H. (1997b). An empirically based microeconomics. Cambridge, U.K.: Cambridge University Press.

Simon, H. (2003). Racionalidad limitada en las Ciencias Sociales: Hoy y Mañana (Trad. W. J. González y M. G. Bonome). En W. Gonzalez (Ed.), Racionalidad, historicidad y predicción en Herbert Simon. España: Wenceslo J.Gonzalez Editor.

Von Neumann, J y Morgenstern, O. (1947). Theory of Games and Economic Behavior. New York: Princeton University Press. 